\title{
Níveis de Lisina para Leitoas Selecionadas Geneticamente para Deposição de Carne Magra na Carcaça, dos 15 aos 30 kg1
}

\section{Dalton de Oliveira Fontes ${ }^{2}$, Juarez Lopes Donzele ${ }^{3}$, Rita Flávia Miranda de Oliveira ${ }^{3}$, Francisco Carlos de Oliveira Silva ${ }^{4}$, Darci Clementino Lopes $^{3}$}

\begin{abstract}
RESUMO - Foram utilizadas 50 leitoas híbridas, com alto potencial genético para deposição de carne magra na carcaça e peso inicial e final de 15,39 \pm 0,59 e 30,93 $\pm 1,72 \mathrm{~kg}$, respectivamente, para avaliar diferentes níveis de lisina. O delineamento experimental foi o de blocos ao acaso, com cinco tratamentos, cinco repetições e dois animais por unidade experimental. Os tratamentos corresponderam a uma ração basal com $19 \%$ de proteína bruta, suplementada com cinco níveis de L-lisina HCl, resultando em rações com 0,95; 1,05; 1,15; 1,25 ; e $1,35 \%$ de lisina total. Observou-se que o ganho de peso e o consumo de lisina diário elevaram-se de forma linear com o aumento do nível de lisina da ração. Houve efeito quadrático dos níveis de lisina sobre o consumo de ração diário e a conversão alimentar, que melhorou até o nível de 1,26\% de lisina total (0,365\%/Mcal de ED) ou 1,13\% (0,328\%/Mcal de ED) de lisina digestível, correspondendo a um consumo estimado de lisina total e digestível de 14,62 g/dia e 13,12 g/dia, respectivamente. Não se observou efeito dos tratamentos sobre a porcentagem de proteína e de água na carcaça e os níveis de uréia no soro sangüíneo, entretanto, houve efeito quadrático sobre a porcentagem de gordura e a taxa de deposição de gordura na carcaça, que diminuíram até o nível de 1,25 e 1,18\% de lisina, respectivamente. Observouse que a taxa de deposição de proteína elevou de forma linear com o aumento do nível de lisina na ração. Os níveis de lisina total que proporcionaram os melhores resultados de desempenho e qualidade de carcaça situaram-se entre 1,18 e 1,35\%. Portanto, concluiu-se que a exigência de lisina total de leitoas dos 15 aos $30 \mathrm{~kg}$ é de 1,26\% ou de 1,13\% de lisina digestível, correspondendo a consumo estimado de lisina total e digestível de 14,6 e 13,1 g/dia, respectivamente.
\end{abstract}

Palavras-chave: carcaça, exigência, fase inicial, genótipo, lisina, uréia

\section{Lysine Levels for Gilts with High Genetic Potential for Lean Gain from 15 to $30 \mathrm{~kg}$}

ABSTRACT - Fifty hybrid gilts, with high genetic potential for lean gain and initial and final weight of $15.39 \pm 0.59$ and $30.93 \pm 1.72 \mathrm{~kg}$, respectively, were used to evaluate diet with different levels of lysine. An experimental design of randomized blocks, with five treatments, five replicates and two animals per experimental unit, was used. The treatments corresponded to a basal diet with $19 \%$ crude protein, supplemented with five levels of HCl-L-Lisine, that resulted in diets with $0.95,1.05,1.15,1.25$ and $1.35 \%$ of lysine. The daily weight gain and daily lysine intake linearly increased with the dietary lysine level. There was quadratic effect of lysine levels on daily feed intake and feed/gain ratio, that increased to the lysine level of $1.26 \%(0.365 \% / \mathrm{Mcal}$ of DE) or $1.13 \%$ $(0.328 \% / \mathrm{Mcal}$ of DE) of true digestible lysine, corresponding to the total and digestible lysine estimated intake of 14.62 and $13.12 \mathrm{~g} /$ day, respectively. There was no effect of treatments on protein and water percentage in carcass and on blood serum urea levels. The treatments influenced quadraticly the fat percentage and fat deposition rate in carcass, that decreased until 1.25 and $1.18 \%$ lysine level, respectively. The protein deposition linearly increased with the dietary lysine level. It was concluded that gilts from 15 to $30 \mathrm{~kg}$ require $1.26 \%$ of total lysine or $1.13 \%$ of digestible lysine, corresponding to a total and digestible lysine estimated intake of 14.6 and $13.1 \mathrm{~g} /$ day, respectively.

Key Words: genotype, gilts, lysine, requirement, initial phase

\section{Introdução}

A melhoria da produtividade no setor suinícola e a demanda de carne magra de alta qualidade pelo consumidor tem desafiado as empresas de genética à seleção e produção de suínos com elevado potencial genético para taxa de crescimento, eficiência alimentar e composição de carcaça.
A introdução de diferentes grupos genéticos no mercado, por outro lado, tornou-se uma preocupação quanto à formulação de rações, pois tem sido documentado em diversos trabalhos (Stahly et al., 1991, Arouca, 2003) que as exigências nutricionais não são as mesmas para suínos com diferentes potenciais genéticos, para deposição de carne magra na carcaça.

\footnotetext{
1 Parte do trabalho de tese de doutorado do primeiro autor - Projeto financiado pela FAPEMIG.

2 Professor do DZO, Escola de Veterinária, UFMG. E.mail: dalton@vet.ufmg.br

3 Professor(a) do Departamento de Zootecnia, UFV.

4 Pesquisador da Empresa de Pesquisa Agropecuária de Minas Gerais - EPAMIG.
} 
Nos últimos anos, as tabelas de exigências nutricionais dos suínos (NRC, 1998, Rostagno, 2000) têm apresentado exigências nutricionais dos animais de acordo com o potencial genético dos animais para deposição de carne magra na carcaça. Por exemplo, Rostagno (2000) recomenda níveis de 1,06 e 1,28\% como exigência de lisina para suínos de médio e alto potencial genético para deposição de carne magra, dos 15 aos $30 \mathrm{~kg}$, respectivamente.

Segundo o NRC (1998), os requerimentos nutricionais dos suínos, além do genótipo, também variam conforme o sexo, a saúde, a temperatura ambiente e a densidade populacional, o que pode explicar as grandes variações encontradas nos trabalhos e nas tabelas quanto aos requerimentos nutricionais dos animais.

No Brasil, existem poucas informações sobre as exigências nutricionais de suínos com elevado potencial genético para produção de carne magra nas diferentes fases de crescimento, visto que, nos últimos anos, diferentes empresas de genética e novos grupos genéticos de suínos foram introduzidos no mercado.

Conduziu-se este trabalho para avaliar o efeito de níveis de lisina sobre o desempenho, o nível de uréia no soro sangüíneo, a composição e as taxas de deposição de gordura e proteína na carcaça de leitoas selecionadas geneticamente para deposição de carne magra, dos 15 aos $30 \mathrm{~kg}$.

\section{Material e Métodos}

O experimento foi conduzido no Setor de Suinocultura do Departamento de Zootecnia da Universidade Federal de Viçosa, utilizando-se 50 leitoas híbridas (irmãs do AGPIC 419), com peso inicial de $15,4 \pm 0,59 \mathrm{~kg}$, distribuídas em delineamento experimental de blocos ao acaso, com cinco tratamentos $(0,95 ; 1,05 ; 1,15 ; 1,25 ;$ e $1,35 \%$ de lisina na ração), cinco repetições e dois animais por unidade experimental. Os blocos foram formados no tempo, cada um com duração média de $22,4 \pm 0,48$ dias. O peso inicial e o parentesco das leitoas foram usados como critério para distribuição dos animais dentro de cada bloco.

Os animais foram alojados em gaiolas metálicas suspensas, com piso e laterais telados, dotadas de comedouros semi-automáticos e bebedouros tipo chupeta, localizadas em prédio de alvenaria com piso de concreto e teto de madeira rebaixado. Foi utilizado um termômetro de máxima e mínima, colocado no interior do galpão, para registro diário da temperatura. As temperaturas médias, mínima e máxima, verificadas no período foram, respectivamente, $22,4 \pm 1,69^{\circ} \mathrm{C}$ e $26,1 \pm 1,72^{\circ} \mathrm{C}$.

Os tratamentos corresponderam a uma ração basal (Tabela 1) com 19\% de proteína bruta e $3.450 \mathrm{kcal}$ de ED, formulada de modo a atender as recomendações nutricionais mínimas sugeridas pelo NRC (1998), suplementada com cinco níveis de LLisina- $\mathrm{HCl} 78,4 \% \quad(0,000 ; 0,127 ; 0,255 ; 0,382$; e $0,510 \%$ ) em substituição ao caulim, que resultou em rações experimentais com um total de 0,$95 ; 1,055$; 1,$15 ; 1,25 ;$ e $1,35 \%$ de lisina, fornecidas à vontade durante todo o período experimental.As composições dos ingredientes utilizados nas rações experimentais, em aminoácidos totais, e da ração basal, em aminoácidos totais e digestíveis, encontram-se na Tabela 2. As análises dos aminoácidos na ração basal, nos ingredientes (milho, farelo de soja e glúten de milho) e nas excretas foram realizadas no Laboratório da Guabi - Mogiana Alimentos S/A - Campinas, SP, utilizando-se analisador de aminoácidos HITACHI modelo 8500 A. A digestibilidade dos aminoácidos sintéticos adicionados à ração foi considerada $100 \%$.

As rações foram pesadas semanalmente, enquanto os animais foram pesados no início e no final do período experimental $(30,93 \pm 1,72 \mathrm{~kg})$, para determinação do consumo de ração e de lisina, do ganho de peso e da conversão alimentar.

No final do experimento, foi coletado o sangue de um animal de cada unidade experimental, retirando-se o soro, para determinação dos teores de uréia, conforme procedimentos descritos por Fontes et al. (2000).

O segundo animal de cada unidade experimental foi abatido, após jejum alimentar (24 horas) e hídrico (12 horas). Os animais foram abatidos por sangramento, depilados e eviscerados. As carcaças inteiras, incluindo cabeça e pés, foram pesadas e a metade esquerda foi triturada por $20 \mathrm{~min}$, em cutter comercial de 30 HP e 1.775 revoluções por minuto. Após homogeneização, foram retiradas amostras e conservadas a $-12^{\circ} \mathrm{C}$. Posteriormente, foram présecas, pré-desengorduradas, moídas e acondicionadas, conforme descrito por Fontes et al. (2000), para análises de umidade, proteína bruta e gordura, realizadas de acordo com Silva (1990).

Um grupo adicional de cinco animais da mesma linhagem, com peso médio de 14,6 $\pm 1,82 \mathrm{~kg}$, foi abatido para determinar a composição da carcaça dos 
Tabela 1 - Composição centesimal da ração basal (\%)

Table 1 - Centesimal composition of the basal diet (\%)

\begin{tabular}{|c|c|}
\hline $\begin{array}{l}\text { Ingredientes } \\
\text { Ingredients }\end{array}$ & $\begin{array}{c}\text { Ração basal } \\
\text { Basal diet }\end{array}$ \\
\hline $\begin{array}{l}\text { Milho } \\
\text { Corn }\end{array}$ & 57,69 \\
\hline $\begin{array}{l}\text { Farelo de soja } \\
\text { Soybean meal }\end{array}$ & 29,41 \\
\hline $\begin{array}{l}\text { Glúten de milho } \\
\text { Corn gluten }\end{array}$ & 2,52 \\
\hline $\begin{array}{l}\text { Óleo vegetal } \\
\text { Vegetable oil }\end{array}$ & 2,50 \\
\hline $\begin{array}{l}\text { Açúcar } \\
\text { Sugar }\end{array}$ & 3,00 \\
\hline $\begin{array}{l}\text { Fosfato bicálcico } \\
\text { Dicalcium phosphate }\end{array}$ & 1,91 \\
\hline $\begin{array}{l}\text { Calcário } \\
\text { Limestone }\end{array}$ & 0,89 \\
\hline $\begin{array}{l}\text { Caulim } \\
\text { Sal } \\
\text { Salt }\end{array}$ & $\begin{array}{l}1,12 \\
0,35\end{array}$ \\
\hline $\begin{array}{l}\text { Premix mineral }^{1} \\
\text { Mineral mix }\end{array}$ & 0,05 \\
\hline $\begin{array}{l}\text { Premix vitamínico }{ }^{2} \\
\text { Vitamin mix }\end{array}$ & 0,12 \\
\hline $\begin{array}{l}\text { Antibiótico } \\
\text { Antibiotic }\end{array}$ & 0,05 \\
\hline $\begin{array}{l}\text { Antioxidante } 4 \\
\text { Antioxidant }\end{array}$ & 0,01 \\
\hline $\begin{array}{l}\text { DL-Metionina }(99 \%) \\
\text { DL-Methionine }\end{array}$ & 0,119 \\
\hline $\begin{array}{l}\text { L-Treonina }(98,5 \%) \\
\text { L-Threonine }\end{array}$ & 0,156 \\
\hline $\begin{array}{l}\text { L-Triptofano }(99 \%) \\
\text { L-Tryptophan }\end{array}$ & 0,026 \\
\hline $\begin{array}{l}\text { L-Valina }(99 \%) \\
\text { L-Valine }\end{array}$ & 0,056 \\
\hline $\begin{array}{l}\text { L-Isoleucina }(99 \%) \\
\text { L-Isoleucine }\end{array}$ & 0,023 \\
\hline $\begin{array}{l}\text { TOTAL } \\
\text { Composição calculada } \\
\text { Calculated composition }\end{array}$ & 100,00 \\
\hline $\begin{array}{l}\text { Energia digestível(kcal/kg) } \\
\text { Digestible energy }\end{array}$ & 3.446 \\
\hline $\begin{array}{l}\text { Proteína bruta }(\%) \\
\text { Crude protein }\end{array}$ & 19,0 \\
\hline $\begin{array}{l}\text { Lisina total }(\%) \\
\text { Total lysine }\end{array}$ & 0,95 \\
\hline $\begin{array}{l}\text { Cálcio }(\%) \\
\text { Calcium }\end{array}$ & 0,90 \\
\hline $\begin{array}{l}\text { Fósforo disponível (\%) } \\
\text { Available phosphorus }\end{array}$ & 0,45 \\
\hline
\end{tabular}

${ }^{1}$ Conteúdo por kg de ração (Content/kg of diet): Mn, 100 g; Fe, 100 g; Zn, 180 g; Cu, 40 g; Co, 1 g; I, 1,9 g; e veículo (vehicle) q.s.p. $1000 \mathrm{~g}$.

${ }^{2}$ Conteúdo/kg de ração (Conten/kg of diet): vit. A, 4.000.000 UI; vit. $\mathrm{D}_{3}, 800.000 \mathrm{UI}$; vit. $\mathrm{E}, 12.000 \mathrm{mg}$; vit $\mathrm{K}_{3}$, $4.000 \mathrm{mg}$; vit. $B_{1}, 1000 \mathrm{mg}$; vit. $B_{2}, 4.000 \mathrm{mg}$; vit. $B_{6}, 1600 \mathrm{mg}$; vit. $B_{12}, 21.000 \mathrm{mcg}$; ácido nicotínico (nicotinic acid), $25.000 \mathrm{mg}$; pantotenato de cálcio (panthotenate of calcium), $16.000 \mathrm{mg}$; Se, $200 \mathrm{mg}$; biotina (biotin), $40 \mathrm{mg}$; antioxidante (antioxidant), $30.000 \mathrm{mg}$; e veículo (vehicle) q.s.p., $1.000 \mathrm{~g}$.

3 Tilosina (Tilosine).

${ }^{4}$ BHT (Beta-hidroxi-tolueno) - Conteúdo (Content) $-100 \mathrm{~g} / \mathrm{kg}$. 
Tabela 2 - Composição dos ingredientes, em aminoácidos totais, e da ração basal, em aminoácidos totais e digestíveis (\%)

Table 2 - Composition of ingredients in total amino acid and composition of basal diet in total and digestible amino acid (\%)

\begin{tabular}{|c|c|c|c|c|c|c|}
\hline $\begin{array}{l}\text { Aminoácido } \\
\text { Amino acid }\end{array}$ & $\begin{array}{l}\text { Milho } \\
\text { Corn }\end{array}$ & $\begin{array}{c}\text { Farelo de soja } \\
\text { Soybean meal }\end{array}$ & $\begin{array}{l}\text { Glúten de milho } \\
\text { Corn gluten }\end{array}$ & & $\begin{array}{r}\text { Ração ba } \\
\text { Basal di }\end{array}$ & \\
\hline & $\begin{array}{c}\mathrm{AAT}^{1} \\
T A A\end{array}$ & $\begin{array}{c}\mathrm{AAT}^{1} \\
T A A\end{array}$ & $\begin{array}{c}\mathrm{AAT}^{1} \\
T A A\end{array}$ & $\begin{array}{c}\mathrm{AAT}^{1} \\
T A A\end{array}$ & $\begin{array}{c}\mathrm{AADV}^{2} \\
R D A A\end{array}$ & $\begin{array}{c}\mathrm{AADA}^{3} \\
A D A A\end{array}$ \\
\hline $\begin{array}{l}\text { Lisina } \\
\text { Lysine }\end{array}$ & 0,22 & 2,71 & 1,03 & 0,950 & 0,821 & 0,773 \\
\hline $\begin{array}{l}\text { Metionina } \\
\text { Methionine }\end{array}$ & 0,13 & 0,52 & 1,30 & 0,379 & 0,333 & 0,311 \\
\hline $\begin{array}{l}\text { Met }+ \text { Cist } \\
\text { Met }+ \text { Cys }\end{array}$ & 0,29 & 1,17 & 2,26 & 0,686 & 0,583 & 0,553 \\
\hline $\begin{array}{l}\text { Treonina } \\
\text { Threonine }\end{array}$ & 0,24 & 1,44 & 1,56 & 0,758 & 0,653 & 0,619 \\
\hline $\begin{array}{l}\text { Isoleucina } \\
\text { Isoleucine }\end{array}$ & 0,25 & 1,64 & 2,00 & 0,700 & 0,607 & 0,568 \\
\hline $\begin{array}{l}\text { Arginina } \\
\text { Arginine }\end{array}$ & 0,35 & 3,58 & 2,00 & 1,305 & 1,266 & 1,229 \\
\hline $\begin{array}{l}\text { Valina } \\
\text { Valine }\end{array}$ & 0,34 & 1,69 & 2,27 & 0,806 & 0,690 & 0,641 \\
\hline $\begin{array}{l}\text { Triptofano } \\
\text { Tryptophan }\end{array}$ & 0,06 & 0,64 & 0,44 & 0,260 & 0,229 & - \\
\hline $\begin{array}{l}\text { Leucina } \\
\text { Leucine }\end{array}$ & 1,01 & 3,36 & 10,63 & 1,839 & 1,626 & 1,535 \\
\hline $\begin{array}{l}\text { Fenilalanina } \\
\text { Phenilalanine }\end{array}$ & 0,36 & 2,21 & 3,81 & 0,954 & 0,813 & 0,771 \\
\hline $\begin{array}{l}\text { Histidina } \\
\text { Hystidine }\end{array}$ & 0,22 & 1,14 & 1,26 & 0,494 & 0,480 & 0,435 \\
\hline $\begin{array}{l}\text { Tirosina } \\
\text { Tyrosine }\end{array}$ & 0,31 & 1,48 & 2,99 & 0,690 & 0,622 & 0,583 \\
\hline
\end{tabular}

suínos no início do experimento. As taxas de deposição de proteína e de gordura nas carcaças foram calculadas comparando-se as composições das carcaças dos animais no início e no fim do período experimental.

As variáveis de desempenho, os níveis de uréia no soro dos animais, a composição de carcaça e as taxas de deposição de proteína e gordura nas carcaças foram submetidos à análise de variância utilizando-se o Sistema de Análises Estatísticas e Genéticas - SAEG (UFV, 1997).

A estimativa de exigência de lisina foi estabelecida por meio de modelos de regressão linear e/ou quadrático.

Para determinação da exigência de lisina digestível, foi considerado o coeficiente de digestibilidade verdadeira da lisina obtido por Fontes et al. (2000).

\section{Resultados e Discussão}

Os resultados de ganho de peso, conversão alimentar, consumo de ração, consumo de lisina e teor de uréia no soro sangüíneo de leitoas na fase inicial de crescimento encontram-se na Tabela 3.

O ganho de peso diário (GPD) aumentou linearmente $(\mathrm{P}<0,01)$, com a elevação do nível de lisina da ração, revelando que suínos com alto potencial genético para deposição de carne magra respondem a altos níveis de lisina na dieta $(1,35 \%$ ou $0,390 \%$ /Mcal de ED), o que proporcionou consumo de lisina total de $16,32 \mathrm{~g} / \mathrm{dia}(3,91 \mathrm{~g} / \mathrm{Mcal}$ de ED) ou $1,22 \%(0,354 \% /$ Mcal de ED) de lisina digestível verdadeira, correspondente ao consumo de lisina digestível de 14,75 g/ dia (3,54 g/Mcal de ED).

Segundo Friesen et al. (1994), a alta exigência de lisina, em porcentagem da dieta, pode ser explicada 
Tabela 3 - Desempenho, consumo de lisina e nível de uréia no soro sangüíneo de leitoas dos 15 aos $30 \mathrm{~kg}$, em função do nível de lisina da ração

Table 3 - Performance, lysine intake and urea level on blood serum of gilts from 15 to $30 \mathrm{~kg}$, in function of the lysine level of diet

\begin{tabular}{|c|c|c|c|c|c|c|}
\hline \multirow[t]{2}{*}{$\begin{array}{l}\text { Parâmetro } \\
\text { Parameter }\end{array}$} & \multicolumn{5}{|c|}{$\begin{array}{c}\text { Nível de lisina total na ração (\%) } \\
\text { Total lysine level of diet }(\%)\end{array}$} & \multirow[t]{2}{*}{$\mathrm{CV}(\%)$} \\
\hline & 0,95 & 1,05 & 1,15 & 1,25 & 1,35 & \\
\hline $\begin{array}{l}\text { Ganho de peso }(\mathrm{g} / \text { dia })^{1} \\
\text { Weight gain }(\text { g/day })\end{array}$ & 638 & 633 & 688 & 743 & 766 & 7,60 \\
\hline $\begin{array}{l}\text { Consumo ração }(\mathrm{g} / \mathrm{dia})^{2} \\
\text { Feed intake (g/day) }\end{array}$ & 1145 & 1053 & 1099 & 1151 & 1209 & 7,00 \\
\hline $\begin{array}{l}\text { Conversão alimentar } \\
\text { Feed:gain ratio }\end{array}$ & 1,80 & 1,66 & 1,60 & 1,55 & 1,58 & 4,60 \\
\hline $\begin{array}{l}\text { Consumo lisina }(\mathrm{g} / \mathrm{dia})^{4} \\
\text { Lysine intake }(\mathrm{g} / \text { day })\end{array}$ & 10,88 & 11,06 & 12,64 & 14,39 & 16,32 & 7,20 \\
\hline $\begin{array}{l}\text { Uréia }(\mathrm{mg} / \mathrm{dL}) \\
\text { Urea }\end{array}$ & 43,3 & 50,62 & 45,10 & 51,40 & 47,25 & 16,32 \\
\hline
\end{tabular}

${ }^{1}$ Efeito linear $(P<0,01)-Y=272,735+366,06 X\left(r^{2}=0,93\right)$ (Linear effect, $\left.P<.01\right)$.

${ }^{2}$ Efeito quadrático $(P<0,04)-Y=3712,81-4789,97+2180,43 X^{2}\left(r^{2}=0,85\right)$ (Quadratic effect, $\left.P<.04\right)$.

${ }^{3}$ Efeito quadrático $(P<0,02)-Y=5,54972-6,32214 X+2,50229 X^{2}\left(r^{2}=0,99\right)$ (Quadratic effect, $\left.P<.02\right)$.

${ }^{4}$ Efeito linear $(P<0,01) \quad-Y=-3,28194+14,2087 X\left(r^{2}=0,95\right)$ (Linear effect, $\left.P<.01\right)$.

pelo baixo consumo diário de ração, característico desses genótipos, assim como por sua elevada capacidade de deposição diária de proteína na carcaça.

Houve efeito quadrático $(\mathrm{P}<0,04)$ dos níveis de lisina sobre o consumo de ração diário (CRD), que diminuiu até o nível de $1,10 \%$ de lisina na ração. Efeitos dos níveis de lisina sobre o consumo de ração de suínos dos 15 aos $30 \mathrm{~kg}$ também foi observado por Coelho et al. (1987). Entretanto, em outros trabalhos (Moretto et al., 2000; Harrison et al., 1990; Lima et al., 1990), não foi evidenciado efeito dos níveis de lisina sobre o consumo de ração diário de suínos na fase inicial de crescimento.

Houve efeito quadrático $(\mathrm{P}<0,02)$ dos tratamentos sobre a conversão alimentar (CA), que melhorou até o nível de $1,26 \%$ de lisina total $(0,365 \% / \mathrm{Mcal}$ de ED) (Figura 1) ou 1,13\% (0,328\%/Mcal de ED) de lisina digestível, correspondente aos consumos de lisina total e digestível de, respectivamente, 14,62 g/dia (3,69 $\mathrm{g} / \mathrm{Mcal}$ de ED) e 13,12 g/dia (3,31 g/Mcal de ED).

O nível de lisina total $(1,26 \%)$ que proporcionou os melhores resultados de CA dos animais foi superior aos obtidos por Lima et al. (1990), que correspondeu a $1,10 \%$ ou $0,323 \% / M c a l$ de ED, e Souza (1997), que correspondeu a $0,84 \%$ ou $0,244 \% / \mathrm{Mcal}$ de ED, para suínos na mesma faixa de peso.

Estes valores estão acima daqueles encontrados por Moretto et al. (2000), que, avaliando níveis de lisina $(0,85$ a $1,25 \%)$ para leitoas puras da raça Landrace, estimou em 1,08\% (0,317\%/Mcal de ED) o nível de lisina que proporcionou os melhores resultados de conversão alimentar.

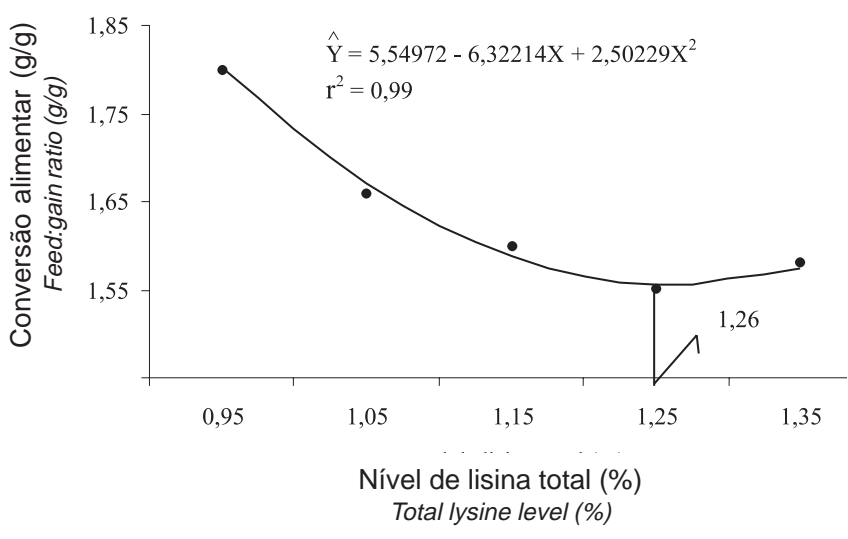

Figura 1 - Efeito do nível de lisina sobre a conversão alimentar de leitoas dos 15 aos $30 \mathrm{~kg}$.

Figure 1 - Effect of lysine level of diet on feed:gain ratio of gilts from 15 to $30 \mathrm{~kg}$.

Comparando os menores valores de CA, de 1,73 e 1,95, obtidos, respectivamente, por Moretto et al. (2000) e Lima et al. (1990), e os valores médios de GPD e CRD, que corresponderam, respectivamente, a 819 e 1470 g (Moretto et al., 2000) e 637 e 1323 g (Lima et al., 1990), com os observados neste trabalho (1,55 para o menor valor de CA e média de 693 e 1131 para GPD e CRD, respectivamente), evidencia-se que suínos em fase inicial de crescimento, com alta capacidade para deposição de carne magra na carcaça, apresentam menor capacidade de consumo de ração, sendo, no entanto, mais eficientes em relação a suínos 
de menor mérito genético, o que pode explicar a alta exigência de lisina, em porcentagem da dieta, desses genótipos, corroborando os relatos de Friesen et al. (1994).

Por outro lado, os resultados obtidos de GPD e CA estão coerentes com aqueles observados por Nan \& Aherne (1994), que estimaram em 14,3 g/dia a exigência de lisina dos suínos dos 9 aos $26 \mathrm{~kg}$ para ganho de peso e eficiência alimentar.

No nível de lisina total $(1,26 \%)$ que proporcionou o melhor resultado de $\mathrm{CA}$, a relação entre os aminoácidos metionina+cistina, treonina, triptofano, valina, isoleusina e a lisina foi de 54, 60, 21, 64 e 56\% . Estes resultados estão próximos daqueles preditos pelo NRC (1998), para suínos de 10 a $50 \mathrm{~kg}$, de 57, 64, 18, 67 e 55\% para os mesmos aminoácidos, e os obtidos por Gatel et al. (1992), ao trabalharem com leitões de 8 a $25 \mathrm{~kg}$, de 58,64 e $20 \%$ para a relação de metionina+cistina, treonina e triptofano e a lisina, respectivamente. Neste mesmo nível, a relação lisina:proteína total foi semelhante $(6,6 \%)$ ao valor proposto pelo NRC (1998), de 6,4\%, para leitões de 10 a $20 \mathrm{~kg}$, mas foi inferior àquela observada por Gatel et al. (1992), de 7,6\%.

O consumo médio diário de lisina (CLD) elevou linearmente $(\mathrm{P}<0,01)$ com o aumento do nível de lisina das rações. De modo similar, Moretto et al. (2000) e Souza (1997) também constataram aumento linear no CLD, decorrente do nível de lisina das rações.

Não se observou efeito $(\mathrm{P}>0,10)$ dos níveis de lisina sobre o teor de uréia no soro sangüíneo dos animais, evidenciando que, nas condições do presente experimento, esse parâmetro não foi efetivo na determinação da exigência de lisina. Considerando que este parâmetro normalmente apresenta alto coeficiente de variação, deduz-se que o número de repetições utilizado neste trabalho para avaliar essa variável tenha sido baixo, o que pode ter contribuído para a falta de consistência destes resultados. Além disso, observou-se que o padrão de consumo de ração dos animais após o período de jejum não foi uniforme, verificando-se grande variação entre os animais das diferentes unidades experimentais, o que também pode ter influenciado estes resultados. É possível que o período de jejum de 24 horas seja inadequado para animais nessa faixa de peso. Do mesmo modo, Friesen et al. (1994) e Moreira et al. (2001) concluíram que o teor de uréia não foi um parâmetro adequado para estimar os requerimentos de lisina de leitoas em crescimento. Por outro lado, nos trabalhos conduzidos por Coelho et al. (1987) e Nan \& Aherne (1994), o nível de uréia foi uma variável que se revelou efetiva na determinação da exigência de lisina para leitões na fase inicial de crescimento.

Os resultados da composição química e das taxas de deposição de proteína e gordura na carcaça de leitoas dos 15 aos $30 \mathrm{~kg}$ são apresentados na Tabela 4.

Não houve efeito $(\mathrm{P}>0,10)$ dos níveis de lisina sobre as porcentagens de água e proteína na carcaça, entretanto, os tratamentos influenciaram de forma quadrática $(\mathrm{P}<0,05)$ a porcentagem de gordura na carcaça, que diminuiu até $12,71 \%$ no nível de 1,25\% de lisina (Figura 2). Neste nível de lisina $(1,25 \%)$, as porcentagens de proteína e de água na carcaça apresentaram valores máximos de 17,23 e $65,35 \%$, respectivamente.

Observou-se efeito quadrático $(\mathrm{P}<0,01)$ dos níveis de lisina sobre a taxa de deposição de gordura (TDG), que diminuiu até o nível de 1,18\% (0,342\%/Mcal de ED) de lisina (Figura 3), e efeito linear $(\mathrm{P}<0,01)$ sobre a taxa de deposição de proteína (TDP), que elevou em razão do aumento dos níveis de lisina da ração.

Os valores dos constituintes da carcaça deste trabalho foram similares aos obtidos por Bikker et al. (1994), que, avaliando níveis de lisina digestível para leitoas com alto potencial genético para deposição de carne magra dos 20 aos $45 \mathrm{~kg}$ de peso vivo, observaram que as maiores porcentagens de proteína e água e a menor de gordura na carcaça corresponderam a 17,6; 66,4; e 12,4\%, respectivamente.

Associando os resultados de deposição de proteína e gordura na carcaça com os de GPD e CA, deduzse que o avanço linear do GPD resultou do aumento linear da TDP, enquanto a melhora da CA até o nível de $1,26 \%$ pode ser atribuída à associação do aumento da TDP com o da redução da TDG até aquele nível. De fato, no nível de $1,25 \%$ de lisina, a porcentagem de energia retida como proteína foi superior e a energia retida como gordura, inferior à dos demais tratamentos.

Considerando que a deposição de proteína é mais eficiente que a de gordura, por agregar maior quantidade de moléculas de água (Kyriazakis et al., 1994), a variação na composição do ganho entre os níveis de 1,25 e $1,35 \%$, em que a TDG aumentou em $23,52 \%$ e a de proteína, em somente $2,16 \%$, explica a piora na CA entre esses dois últimos níveis.

O nível de 1,35\% de lisina total que proporcionou os melhores resultados de ganho de peso diário e taxa 
Tabela 4 - Composição de carcaça e taxas de deposição de gordura e de proteína na carcaça de leitoas dos 15 aos 30 kg, em função do nível de lisina da ração

Table 4 - Carcass composition, fat and protein deposition rate in carcass of gilts from 15 and $30 \mathrm{~kg}$, in function of the lysine level of diet

\begin{tabular}{|c|c|c|c|c|c|c|}
\hline \multirow[t]{2}{*}{$\begin{array}{l}\text { Parâmetro } \\
\text { Parameter }\end{array}$} & \multicolumn{5}{|c|}{ Nível de lisina total na ração (\%) } & \multirow[t]{2}{*}{$\mathrm{CV}(\%)$} \\
\hline & 0,95 & 1,05 & 1,15 & 1,25 & 1,35 & \\
\hline \multicolumn{7}{|c|}{ Composição de carcaça (\%) } \\
\hline \multicolumn{7}{|c|}{ Carcass composition } \\
\hline Água & 62,73 & 63,87 & 64,24 & 65,35 & 63,86 & 2,84 \\
\hline \multicolumn{7}{|l|}{ Water } \\
\hline Proteína & 16,91 & 16,99 & 17,16 & 17,23 & 17,16 & 3,07 \\
\hline \multicolumn{7}{|l|}{ Protein } \\
\hline Gordura $^{1}$ & 16,19 & 14,89 & 14,30 & 12,71 & 14,10 & 7,30 \\
\hline \multicolumn{7}{|l|}{ Fat } \\
\hline \multicolumn{7}{|c|}{ Taxa de deposição na carcaça (g/dia) } \\
\hline \multicolumn{7}{|c|}{ Carcass deposition rate (g/day) } \\
\hline Proteína ${ }^{2}$ & 109,97 & 110,37 & 121,86 & 132,26 & 135,13 & 12,86 \\
\hline \multicolumn{7}{|l|}{ Protein } \\
\hline Gordura $^{3}$ & 129,31 & 111,82 & 111,77 & 97,02 & 119,84 & 15,51 \\
\hline \multicolumn{7}{|l|}{ Fat } \\
\hline \multirow{2}{*}{\multicolumn{7}{|c|}{$\begin{array}{l}\text { Energia retida na carcaça }(\mathrm{kcal} / \mathrm{dia})^{4} \\
\text { Retained energy in carcass }(\mathrm{kcal} / \text { day })\end{array}$}} \\
\hline & & & & & & \\
\hline Total & 1831 & 1669 & 1732 & 1653 & 1883 & \\
\hline \multicolumn{7}{|l|}{ Total } \\
\hline Proteína $(\%)$ & 33,63 & 37,03 & 39,38 & 44,83 & 40,20 & \\
\hline \multicolumn{7}{|l|}{ Protein } \\
\hline Gordura(\%) & 66,36 & 62,97 & 60,62 & 55,17 & 59,80 & \\
\hline \multicolumn{7}{|l|}{ Fat } \\
\hline
\end{tabular}

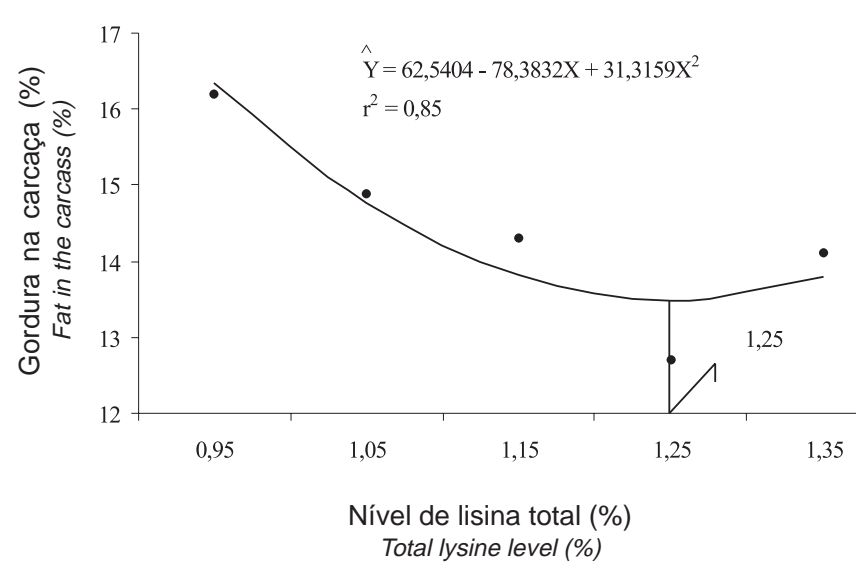

Figura 2 - Efeito do nível de lisina sobre a porcentagem de gordura na carcaça de leitoas aos $30 \mathrm{~kg}$.

Figure 2 - Effect of lysine level of diet on fat percentage on carcass of gilts at $30 \mathrm{~kg}$.

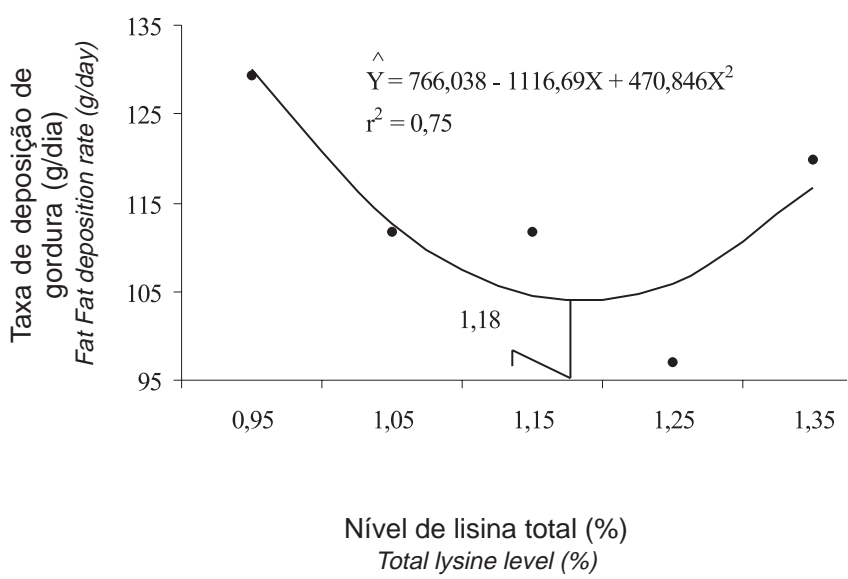

Figura 3 - Efeito do nível de lisina sobre a taxa de deposição de gordura na carcaça de leitoas dos 15 aos $30 \mathrm{~kg}$.

Figure 3 - Effect of lysine level of diet on fat deposition rate in carcass of gilts from 15 to $30 \mathrm{~kg}$. 
de deposição de proteína na carcaça e aquele que proporcionou os melhores resultados de conversão alimentar $(1,26 \%)$ estão acima das recomendações encontradas na maioria dos trabalhos e das tabelas de exigência nutricionais de suínos.

\section{Conclusões}

A exigência de lisina total de leitoas selecionadas geneticamente para deposição de carne magra na carcaça, dos 15 aos $30 \mathrm{~kg}$, é de $1,26 \%$ ou $1,13 \%$ de lisina digestível verdadeira, correspondendo a um consumo estimado de lisina total e digestível de 14,62 e $13,12 \mathrm{~g} / \mathrm{dia}$, respectivamente.

\section{Agradecimento}

À Agroceres Nutrição Animal e Agroceres - Pic, pela cooperação.

\section{Literatura Citada}

AEC -TABLES. Recomendações para nutrição animal. 5.ed. Antony Cedex: Rhône-Poulenc Animal Nutrition. 86 p. 1987.

AGRICULTURAL RESEARCH COUNCIL - ARC. The nutrient requeriments of the pig. Sloug: Commonwealth Agricultural Bureaux, 1981. 307p.

AROUCA, C.L.C. Exigências de lisina para suínos machos castrados de dois grupos genéticos, na fase de terminação tardia. Belo Horizonte: Universidade Federal de Minas Gerais, 2003. 50p. Dissertação (Mestrado em Zootecnia) Universidade Federal de Minas Gerais, 2003.

BIKKER, P.; VERSTEGEN, M.W.A.; CAMPBELL, R.G. et al. Digestible lysine requirements of gilts with high genetic potential for lean gain, in relation to the level of energy intake. Journal of Animal Science, v.72, n.7, p.17441753, 1994.

COELHO, L.S.S.; COSTA, P.M.A.; SILVA, M.A. et al. Exigências de lisina de suínos dos 15 aos 30 kg alimentados com rações com diferentes densidades calóricas e nível sub-ótimo de proteína. Revista Brasileira de Zootecnia, v.16, n.1, p.72-80, 1987.

COELHO, L.S.S.; GADELHA, J.A.; BASTOS, F.J.S. Exigências de lisina de suínos na fase de 10 a $20 \mathrm{~kg}$ em condições brasileiras. In: REUNIÃO ANUAL DA SOCIEDADE BRASILEIRA DE ZOOTECNIA, 28., 1991, João Pessoa. Anais... João Pessoa: Sociedade Brasileira de Zootecnia, 1991b. p.387.

FONTES, D.O.; DONZELE, J.L.; FERREIRA, A.S. et. al. Níveis de lisina para leitoas selecionadas geneticamente para deposição de carne magra, dos 60 aos $95 \mathrm{~kg}$. Revista Brasileira de Zootecnia, n.29, v.3, p.784-793, 2000.
FRIESEN, K.G.; NELSSEN, J.L., GOODBAND, R.D. et al. Amino acid requirements for high-lean growth gilts. In: ANNUAL MEETING OF THE AMERICAN ASSOCIATION OF SWINE PRACTITIONERS, 25., 1994, Chicago. Proceedings... Chicago: ASSP, 1994. p.312-320.

GATEL, F.; BURON, G.E.; FÉKÉTE, J. Total amino acid requeriments of weaned piglets 8 to $25 \mathrm{~kg}$ live weight given diets based on wheat na soya-bean meal fortified with free amino acids. Animal Production, v.54, part. 2, p.281-287. 1992.

HARRISON, M.D.; CAMPBELL, D.R.; WALKER, W.R. et al. Effects of dietary protein and crystalline lysine on performance of starting and finishing swine. Pig News and Information, v.11, n.1, p.115, 1990.

INSTITUT NATIONAL DE LA RECHERCHE AGRONOMIQUE - INRA. Alimentácion de los animales monogastricos, cerdos, conejos e aves. Madrid: MundiPrensa, 1985. 283p.

KYRIAZAKIS, I.; DOTAS, D.; EMMANS, G.C. The effects of breed on the relationship between feed composition and the efficiency of protein utilization in pigs. British Journal of Nutrition, v.71, n.5, p.849-859, 1994.

LIMA, J.A.F.; PEREIRA, J.A.A.; COSTA, P.M.A. et al. Efeito da idade de desmama sobre as exigências de lisina para leitões na fase inicial de crescimento ( 15 a $30 \mathrm{~kg}$ ). Revista Brasileira de Zootecnia, v.19, n.5, p.390-399, 1990.

MORETTO, V.; DONZELE, J.L.; OLIVEIRA, R.F.M. et al. Níveis de lisina dietética para suínos da raça Landrace dos 15 aos $30 \mathrm{~kg}$. Revista Brasileira de Zootecnia, v.29, n.3, p.803-809, 2000.

NAN, D.S.; AHERNE, F.X. The effects of lysine:energy ratio on the performance of weanling pigs. Journal of Animal Science, v.72, n. 5, p.1247-1256, 1994.

NATIONAL RESEARCH COUNCIL - NRC.. Nutrient requirements of swine. 10.ed. Washington, D.C. National Academy Press, 1998. 189p.

SILVA, D.J. Análise de alimentos: métodos químicos e biológicos. 2.ed. Viçosa, MG: Universidade Federal de Viçosa, 1990. 166p.

SOUZA, A.M. Exigências nutricionais de lisina para suínos mestiços, de 15 a $95 \mathrm{~kg}$ de peso. Viçosa, MG: Universidade Federal de Viçosa, 1997. 81p. Dissertação (Mestrado em Zootecnia) - Universidade Federal de Viçosa, 1997.

STAHLY, T.S.; CROMWELL, G.L.; TERHUNE, D. Responses of high, medium and low lean growth genotypes to dietary amino acid regimen. Journal Animal Science, v.69 (suppl. 1), p.364 (Abstr.), 1991.

UNIVERSIDADE FEDERAL DE VIÇOSA (UFV). SAEG Sistemas de Análises Estatísticas e Genéticas. Versão 7.1. Viçosa, MG: 1997. 150p. (Manual do usuário) 